\section{Cocrystal formation between trimethoprim and sulfamethoxazole by sealed-heating method}

\section{Erizal Zaini ${ }^{1}$, Cahyati Sumirtapura Yeyet ${ }^{1}$,}

Nurono Soewandhi Sundani ${ }^{1}$, Halim Auzal ${ }^{2}$

${ }^{1}$ Bandung Institute of Technology, School of Pharmacy, farmasi@itb.ac.id, Bandung, West Java, 40132, Indonesia, ${ }^{2}$ Faculty of Pharmacy, Universitas Andalas, Indonesia, E-mail:erizal faua@yahoo.co.id

Equimolar cocrystal formation between trimethoprim and sulfamethoxazole by sealed heating methods was carried out. When trimethoprim and sulfamethoxazole were heating at a molar ratio $1: 1$, new powder X-ray diffraction (PXRD) interferences peaks were observed in addition to PXRD interference peaks of each component. Effect of heating time on trimethoprim-sulfamethoxazole equimolar cocrystal was investigated by using PXRD, diffrential scanning calorimetry (DSC) and Fourier transform infrared spectroscopy. Cocrystal obtained by sealed heating method at temperature $160{ }^{\circ} \mathrm{C}$ had the same PXRD pattern and DSC thermogram with cocrystal from cocrystallization and melting method. These result indicated that heating could induced the formation of cocrystal.

Keywords: trimethoprim, sulfamethoxazole, cocrystal

\section{P10.01.01}

Acta Cryst. (2008). A64, C490

\section{First report of natural oxyallanite: Oxidation and} dehydration during welding of volcanic tuff

Mihoko Hoshino, Mitsuyoshi Kimata, Norimasa Nishida, Masahiro Shimizu, Takeshi Akasaka

University of Tsukuba, Earth Evolution Sciences, Tennoudai 1-1-1, Tsukuba, Ibaraki, 305-8572, Japan, E-mail:hossy716@geol.tsukuba.ac.jp

The oxidation of $\mathrm{Fe}^{2+}$ to $\mathrm{Fe}^{3+}$, the release of $\mathrm{H}_{2}$, and the concomitant replacement of $\mathrm{OH}^{-}$by $\mathrm{O}^{2-}$ would produce an oxy-equivalent of alla nite $\left(\mathrm{CaREEAl}_{2} \mathrm{Fe}^{2+} \mathrm{Si}_{3} \mathrm{O}_{11} \mathrm{O}(\mathrm{OH})\right.$ ) (Dollase 1973). The reaction $\mathrm{Fe}^{2+}$ $+\mathrm{OH}^{-}-\mathrm{Fe}^{3+}+\mathrm{O}^{2-}+1 / 2 \mathrm{H}_{2}$ is formally equivalent to the oxy-reaction observed in other hydrous $\mathrm{Fe}^{2+}$-bearing silicate minerals, such as mica and amphiboles (e.g., Hogg \& Meads 1975; Ferrow 1987). However, occurrence of oxyallanite $\left(\mathrm{CaREEAl}_{2} \mathrm{Fe}^{3+} \mathrm{Si}_{3} \mathrm{O}{ }_{11} \mathrm{O}(\mathrm{O})\right)$ in natural environment has never been reported. The purpose of the preset study is to discuss occurrence of natural oxyallanite. Chemical compositions and crystal structures of the allanites from two rhyolitic rocks--(1) Youngest welded tuff from Toba (YTT), Sumatra, Indonesia and (2) volcanic ash from SK100 (SK100-VAB), Niigata, Japan--were determined by electron microprobe analysis and single crystal diffractometer, respectively. Despite the close similarity, in chemical composition, between YTT allalnites and SK100 ones, their unit-cell parameters are distinct from each other. The former have shorter $b$ axis and longer $c$ axis and larger $\beta$ value in comparison with cell parameters of the latter. FT-IR analysis shows that YTT allanites have both the smaller $\mathrm{OH}$-absorption band area and the shift of its bands to higher wavenumbers as compared to SK100 ones. Welding of the ash flow tuff including the allanites preformed in Youngest Toba welded tuff would cause them to undergo oxidations, dehydration and replacement. The sequential reaction would result in producing the present YTT allanite, namely oxyallanite. Although oxyallanite was only obtained by heating the natural allanite (e.g., Armbruster et al. 2006), this study first reports that oxyallanite may commonly occur in welded rocks at high temperatures.

Keywords: oxyallanite, welded tuff, volcanic ash beds

\section{The effects of $\mathrm{F}-\mathrm{OH}$ replacement on the compression of super hydrous phase B structure}

Takahiro Kuribayashi $^{1,3}$, Toshiro Nagase ${ }^{4}$, Hiroshi Kojitani², Masaki Akaogi ${ }^{2}$, Russell Hemley ${ }^{3}$, Ho-k Mao ${ }^{3}$, Yasuhiro Kudoh ${ }^{1}$

${ }^{1}$ Tohoku University, Department of Earth Science, 6-3, Aramaki Aza Aoba, Aoba-ku, Sendai, Miyagi, 980-8578, Japan, ${ }^{2}$ Department of Chemistry, Gakushuin University, Tokyo 171-8588, Japan, ${ }^{3}$ Geophysical Laboratory, Carnegie Institution of Washington, Washington DC. 20015, USA, ${ }^{4}$ The Tohoku University Museum, Tohoku University, Sendai 980-8578, Japan, E-mail:t-kuri@mail.tains.tohoku.ac.jp

Super hydrous phase B (SUP-B), $\mathrm{Mg}_{1} 0 \mathrm{Si}_{3} \mathrm{O}_{14}(\mathrm{OH})_{4}$, is known as one of dense hydrous magnesium silicate minerals (DHMS) in Earth Science category. Physical properties of SUP-B are investigating to understand the structure of Earth's interior, since lots of previous works on phase study showed that SUP-B is stable under the cold slab conditions. Also, according to previous studies including ourselves, DHMS phases have a simple trend in the relationship between bulk modulus and some indexes such as density, the filing factor and so on. In these relationships, the F-OH replacement effects on the compression of these phases have not been clarified yet. Since F should be included in natural minerals instead of $\mathrm{OH}$, it is important to understand F-OH replacement effects on some physical properties. In this study, for the structure of super hydrous phase B, highpressure single crystal $\mathrm{x}$-ray diffraction experiments were conducted to investigate the $\mathrm{F}-\mathrm{OH}$ replacement effects on the compression. Fluorine end member SUP-B phase (F-SUP-B) was synthesized using a multi anvil apparatus installed in Gakushuin University under $21 \mathrm{GPa}$ and $1400 \mathrm{C}$ conditions. Single crystal of F-SUP-B (0.04 x $0.04 \times 0.03 \mathrm{~mm}^{3}$ ) was used for X-ray diffraction experiments at the BL-10A beam line in Photon Factory, KEK, Japan. Lattice parameters of this phase were measured at $0.0001,1.5,2.7,4.0,5.0,6.4$ and 7.4 $\mathrm{GPa}$. The isothermal bulk modulus of F-SUP-B, calculated using the Birch-Murnaghan EoS (assuming $\mathrm{K}^{\prime}=4$ ), was $\mathrm{K}=153$ (3) $\mathrm{GPa}$. This value was slightly larger (7\%) than that $(\mathrm{K}=145(1) \mathrm{GPa})$ of $\mathrm{OH}$ SUP-B. This is consistent with the predicted values from the case of norbergite which is known as other DHMS. The privation of weak hydrogen bonding in F-SUP-B structure caused its elastic hardening.

Keywords: high-pressure X-ray diffraction, single-crystal $X$-ray methods, synchroton radiation

\section{P10.01.03}

Acta Cryst. (2008). A64, C490-491

Melt inclusion geothermometry and crystallography of calcic-plagioclases

Babita Rani Choudhary, Gajananrao Narayanrao Jadhav

IITBombay,Powai, Earth Sciences, choudhary.r.babita@gmail.com, Mumbai, Maharashtra, 400076, India, E-mail : choudhary.r.babita@gmail. com

Babita Rani Choudhary (choudhary.r.babita@gmail.com) Dr. Gajananrao Narayanrao Jadhav (jadhav@iitb.ac.in) Department of Earth Sciences, IIT Bombay, Powai, Mumbai-400076, Maharashtra, India The crystallizing temperature works as a catalyst to initiate the nucleation of specific type of crystal development. Plagioclase phenocrysts have trapped small mass of magma as melt inclusions in the zoned as well as twinned variety, which indicate the geothermometric sequences of melt inclusions. To observe the kinetics of crystal-thermometry, we examined the zoned calcicplagioclase phenocryst, from Deccan basalt samples collected from 


\section{Poster Sessions}

the Mahabaleshwar area of Maharashtra state, India. The feldspar phenocrysts contain different types of melt inclusions. These melt inclusions significantly show variation in melting temperature. Presence of different types of melt inclusions along crystal boundaries indicated the change in composition and this may be the function of temperature. Different types of melt inclusions found in plagioclase phenocrysts are amorphous and crystalline (monophase, biphase and multiphase).Variation in the commodity of these melt inclusions, itself reveals the immiscibility as well as the degassing phenomena of magma. An attempt has been made to correlate the melt inclusion geothermometry with the evolution pattern of magma/melt that of calcic-plagioclase phenocrysts present in a deccan basalts. Petrographic results were confirmed by the XRD and Cathodoluminescence studies. Heating stage experiment was carried out to find out the formation temperatures/melting temperatures of melt inclusions.

Keywords: geothermometry, melt inclusion, crystallography

\section{P10.02.04}

Acta Cryst. (2008). A64, C491

\section{Calculation of graphs representing crystal structures}

\section{Hosung Kim$^{1}$, Sujin Chung ${ }^{2}$}

${ }^{1}$ Chonnam National University, Dept. of Materials and Engineering, 418 B27(College of Engneering Bldg) 300 Yongbong-dong, Buk-gu, Gwangju, Gwangju, 500-757, Korea (S), ${ }^{2}$ School of Materials Science and Engineering, Seoul National University, Seoul 151-742, Korea, E-mail : icosahedron@hanmail.net

Some crystal structures can be described by certain graphs (Chung \& Hahn, Acta Cryst. A31 (1975) S.J. Chung, Hahn \& Klee, Acta Cryst. A40 (1984) 42-50). In this method, each periodic infinite net can be expressed by a labelled directed finite graph which is called also labelled quotient graph. Each point and each line in the quotient graph corresponds to a set of equivalent vertices and edges in the three periodic net. Quotient graphs and spanning trees can obtained with given numbers of vertices and edges in this calculation. We use the determinant and trace of the matrix representing the quotient graph for the criteria of isomorphism of quotient graph. Special algorithm is applied to this program because the isomorphism of quotient graphs seriously delays the computation time with increase of the number of vertices and edges. The labelling to the quotient graphs can be applied. The structure of the network also can be obtained from the labelled graphs with least square fitting. A computation method for the enumeration of three periodic regular nets with a given number of vertices and edges will be discussed in detail.

Keywords: graph, network, crystal structure

\section{P10.02.05}

\section{Hybrid twins in minerals}

Giovanni Ferraris ${ }^{1}$, Massimo Nespolo ${ }^{2}$

${ }^{1}$ Università di Torino, Scienze Mineralogiche e Petrologiche, Via Valperga Caluso 35, Torino, Torino, 10125, Italy, ${ }^{2}$ LCM3B UMR-CNRS 7036 Nancy Universite’ France, E-mail: giovanni.ferraris@unito.it

Twins in which the lattice nodes (quasi) restored by the twin operation belong to more than one sublattice are termed hybrid twins [1]. The fraction of (quasi) restored nodes takes into account all these sublattices and an effective twin index $n_{E}$ is defined. In Friedelian twins (twin index not higher than 6), the hybrid character shows that the choice of the sublattice is not unique. In non-Friedelian twins, $n_{E}$ allows a rationalization of these twins within the framework of the classical reticular theory [2]. A survey of twins in minerals has shown that a number of them should be reinterpreted as hybrid twins. For high-symmetry twins (cubic and uniaxial minerals), this is normally the case for twin elements of relatively high indices. E.g., (031) twin in cassiterite (four sublattices, $n_{E}=3.8$ ), (311) twin in nickeline (three sublattices, $n_{E}=6.3$ ), (203) twin in maucherite (three sublattices, $n_{E}=5.83,(241)$ twin in diaphorite (two sublattices, $n_{E}=4.0$ ), and [313] twin in staurolite (two sublattices, $n_{E}=6.0$ ). For lower symmetry minerals, even low-index twin elements may correspond to a non-Friedelian twin that is better interpreted as hybrid twins. E.g., (110) twin in becquerelite (three sublattices, $n_{E}=3.0$ ), (110) twin in geocronite (three sublattices, $n_{E}=3.0$ ), and (211) twin in cryolite (three sublattices, $n_{E}=3.7$ ). Examples of Friedelian twin that can be interpreted as hybrid twins have also been found; e.g., (011) twin in anhydrite: here one sublattice corresponds to index 4 and obliquity $0.7^{\circ}$, another sublattice to index 3 and obliquity $3.1^{\circ}$. If both sublattices are taken into account, one obtains $n_{E}=2.0$.

[1] Nespolo M, Ferraris G (2006). Acta Cryst. A62, 336.

[2] Friedel G (1926) Leçons de cristallographie. Berger-Levrault.

Keywords: twinning, hybrid twins, effective twin index

\section{P10.02.06}

Acta Cryst. (2008). A64, C491-492

\section{Atomic displacements of tetrahedral cations in garnets}

Mami Shimokawa $^{1}$, Akihiko Nakatsuka $^{1}$, Takashi Kanayama ${ }^{1}$,

Noriaki Nakayama $^{1}$, Kazuake Iishi ${ }^{1}$, Akira Yoshiasa ${ }^{2}$

${ }^{1}$ Yamaguchi University, Science and Engineering, 2-16-1 Tokiwadai, Ube, Yamaguchi, 755-8611, Japan, ${ }^{2}$ Kumamoto University, 2-39-1 Kurokami, Kumamoto 860-8555, Japan, E-mail:tuka@po.cc.yamaguchi-u.ac.jp

We had reported that in most of reported garnets, the root meansquare displacements (RMSD) of tetrahedral $(Z)$ cations are the smallest in the directions of adjacent dodecahedral $(X)$ cations (direction 1), parallel to a crystal axis, because of strong $X-Z$ repulsions and the largest in the directions of the remaining two crystal axes (direction 2). However, we recently found that RMSD of $Z$ cation in $\mathrm{Pb}$ vanadate garnets $\left(\mathrm{NaPb}_{2} M_{2} \mathrm{~V}_{3} \mathrm{O}_{12} ; M\right.$ is divalent cations) is the largest in the direction 1 , in which adjacent $X$ cations exist, and the smallest in the direction 2 , in which no adjacent atoms exist, in contradiction to the above general tendency. In the present study, to examine whether this peculiar feature in $\mathrm{Pb}$ vanadate garnets is due to the positional disorder of $Z$ cation toward the direction 1 caused by lone pair electrons of $\mathrm{Pb}^{2+}$ in $X$ site, we perform the structure refinements of $\mathrm{NaSr}_{2} \mathrm{Mg}_{2} \mathrm{~V}_{3} \mathrm{O}_{12}$, having $X$ cation $\left(\mathrm{Sr}^{2+}\right)$ without lone pair electrons and expected to possess $X-Z$ repulsion comparable to those in $\mathrm{Pb}$ vanadate garnets, at $298 \mathrm{~K}$ and $\mathrm{NaPb}_{2} \mathrm{Mg}_{2} \mathrm{~V}_{3} \mathrm{O}_{12}$ in the range of 83-298 K. Moreover, the crystal structures of uninvestigated $\mathrm{Ca}$ vanadate garnets $\left(\mathrm{NaCa}_{2} \mathrm{Co}_{2} \mathrm{~V}_{3} \mathrm{O}_{12}\right.$, $\mathrm{NaCa}_{2} \mathrm{Ni}_{2} \mathrm{~V}_{3} \mathrm{O}_{12}$ ) are refined at $298 \mathrm{~K}$. RMSD $/ \mathrm{RMSD}_{2}$ ratios of $Z$ cations $\left(\mathrm{V}^{5+}\right)$ in $\mathrm{NaCa}_{2} \mathrm{Co}_{2} \mathrm{~V}_{3} \mathrm{O}_{12}$ and $\mathrm{NaCa}_{2} \mathrm{Ni}_{2} \mathrm{~V}_{3} \mathrm{O}_{12}$ are below 1.0 according to the general tendency, whereas that in $\mathrm{NaSr}_{2} \mathrm{Mg}_{2} \mathrm{~V}_{3} \mathrm{O}_{12}$ is much larger than 1.0 as in $\mathrm{Pb}$ vanadate garnets, where $\mathrm{RMSD}_{1}$ and $\mathrm{RMSD}_{2}$ are RMSD's in the directions 1 and 2, respectively. The $U_{\text {eq }}$ value in $Z$ cation of $\mathrm{NaPb}_{2} \mathrm{Mg}_{2} \mathrm{~V}_{3} \mathrm{O}_{12}$ can be extrapolated to 0 at $0 \mathrm{~K}$, and no separation of electron density peak on $Z$ site can be observed on Fourier map. These show that the peculiar atomic displacement behavior of $Z$ cation in $\mathrm{Pb}$ vanadate garnets cannot be due to its positional disorder.

Keywords: crystal chemistry, thermal vibration, single-crystal 